\title{
Effects of L-carnitine supplementation on nutritional, immunological, and cardiac parameters in hemodialysis patients: a pilot study
}

\author{
Haruki Sada ${ }^{1 *}$, Akihiko Kato ${ }^{2}$, Ryo Sumimoto ${ }^{3}$, Hiromitsu Ohmori ${ }^{4}$ and Hideki Ohdan ${ }^{1}$
}

\begin{abstract}
Background: L-carnitine is an essential compound that facilitates the transport of long-chain fatty acid across the inner mitochondrial membrane for $\beta$-oxidation. However, the effect of L-carnitine supplementation remains to be fully explored in patients with chronic kidney disease. We aimed in this study to determine the multidirectional effects of L-carnitine supplementation on clinical parameters in more detail.

Methods: We orally administered L-carnitine to maintain serum-free carnitine levels within the normal range (30 to $70 \mu \mathrm{mol} / \mathrm{L}$ ) for 6 months in 21 hemodialysis (HD) patients (age, $74 \pm 11$ years; time on HD, $60 \pm 84$ months).

Results: L-carnitine supplementation significantly increased serum transferrin from $155 \pm 41$ to $175 \pm 48 \mathrm{mg} / \mathrm{dL}$ $(p<0.01)$ and retinol-binding protein from $8.9 \pm 2.5$ to $10.0 \pm 3.4 \mathrm{mg} / \mathrm{dL}(p<0.05)$. The triceps skinfold thickness was also significantly increased $(p<0.05)$, while the skeletal muscle mass in limbs and handgrip strength was not. L-carnitine enhanced natural killer (NK) cell activity at the $\mathrm{E}$ (effector cell)/T (target cell) ratio of 20:1 from $17.3 \pm 14.1$ to $20.8 \pm 17.7 \%(p<0.01)$. In addition, L-carnitine improved left ventricular functional shortening $(p<0.01)$ with a significant decrease of brain natriuretic peptide (BNP) from $621.4 \pm 666.8$ to $412.0 \pm 426.0 \mathrm{pg} / \mathrm{mL}(p<0.05)$.

Conclusions: These findings suggest that oral L-carnitine treatment improves immunological and cardiac markers in HD patients. In contrast, L-carnitine did not change the skeletal mass-related parameters during the 6-month follow-up.
\end{abstract}

Keywords: Hemodialysis, L-carnitine, Sarcopenia, Natural killer cell activity, Left ventricular function

\section{Background}

Protein-energy wasting (PEW) comprises excessive losses of body protein mass and energy reserves, and it is associated with high morbidity and mortality in patients with chronic kidney disease (CKD) [1]. There are many causes of PEW such as inadequate nutrient intake, increased nutrient losses from the dialysate, inflammation, oxidant stress, carbonyl stress, disorders of anabolic or catabolic hormones, and acidemia [1].

L-carnitine is a natural compound that is synthesized from lysine and methionine. L-carnitine is essential in

\footnotetext{
* Correspondence: z011028sangyo@yahoo.co.jp

'Department of Gastroenterological and Transplant Surgery, Applied Life Sciences, Institute of Biomedical and Health Sciences, Hiroshima University, 1-2-3 Kasumi, Minami-ku, Hiroshima 734-8551, Japan

Full list of author information is available at the end of the article
}

the transfer of long-chain fatty acids into the mitochondria for $\beta$-oxidation. When carnitine deficiency develops, long-chain fatty acids are not available for $\beta$-oxidation or energy production, which causes excessive lipid accumulation in organs such as the muscle. Carnitine is also necessary to maintain the function and morphology of the brown adipose tissue [2]. Approximately $95 \%$ of the carnitine pool is present in the skeletal and cardiac muscle, $2-3 \%$ in the liver and kidneys, and only $0.5-$ $1 \%$ in extracellular fluid [3].

Dialysis patients are especially at high risk for carnitine deficiency due to poor intake of sources of dietary carnitine such as red meat, reduced biosynthesis in the kidneys, and diffusive loss from the dialysate. In incident hemodialysis (HD) patients, the plasma carnitine level decreases within the first week of the treatment, with a 
continual decrease over the first 12 months of treatment [4]. The carnitine content of the skeletal muscle also decreases in hemodialysis patients and is inversely correlated with time on $\mathrm{HD}[4,5]$.

Metabolism of skeletal muscle is carnitine-dependent because fatty acid oxidation is the main source of energy in the muscular cells. However, it remains to be fully determined whether or not L-carnitine supplementation improves muscle power, physical capacity, and muscular symptoms.

The aim of the present study is to further clarify the effect of L-carnitine supplementation on clinical parameters in HD patients. We prospectively administered Lcarnitine orally to maintain free carnitine levels within the normal range for 6 months and examined the impact of L-carnitine supplementation on nutritional, immunological, inflammatory, and cardiac markers in more detail.

\section{Methods}

\section{Patients}

This study was conducted in a single dialysis center (National Hospital Organization Yanai Medical Center, Yamaguchi, Japan). At first, $26 \mathrm{HD}$ patients, who had given their consent, were enrolled in this study. There was no patient who had received any L-carnitine supplementation before the entry. The study design had been approved by the appropriate ethics review boards of the institution within which the study was undertaken, and it conformed to the provisions of the Declaration of Helsinki.

All patients had been subjected to regular HD using polysulfone dialyzer membranes with bicarbonate buffers for 3 to $4 \mathrm{~h}$ three times per week.

\section{L-carnitine supplementation}

We originally modified the initial dose of oral L-carnitine according to dry weight (DW) to maintain serum level within normal range without risk, since excess L-carnitine can be converted by intestinal microbiota into trimethylamine-N-oxide (TMAO), a potential promoter of coronary arteriosclerosis [6]. When DW was higher than $50 \mathrm{~kg}$, we initially administered $400 \mathrm{mg} /$ day once a day, while when DW ranged from 30 to $50 \mathrm{~kg}$, we administered $300 \mathrm{mg} /$ day. Also, if DW was less than $30 \mathrm{~kg}$, we started with the dose of $200 \mathrm{mg} /$ day.

We then measured predialysis serum carnitine levels every month for the initial 3 months. When the total carnitine concentration exceeded the normal upper limit $(\geq 70 \mu \mathrm{mol} / \mathrm{L}$ ), we decreased the dose by $100 \mathrm{mg}$ daily until the next measurement. In contrast, when the serum level of total carnitine was less than the lower limit $(<30 \mu \mathrm{mol} / \mathrm{L})$, we increased the dose by $100 \mathrm{mg} /$ day until the next measurement.

\section{Blood sampling and laboratory examinations}

Blood samples were drawn from the arterial site of the arteriovenous fistula at each dialysis session after a 2-day interval at 0,3 , and 6 months after the enrollment. Blood cell counts, blood urea nitrogen, serum creatinine, total protein, albumin, C-reactive protein (CRP), lipids (low-density lipoprotein (LDL) cholesterol, high-density lipoprotein (HDL) cholesterol, and triglycerides), hemoglobin, ammonia, and brain natriuretic peptide (BNP) were measured by standard laboratory techniques using an auto-analyzer. We calculated $K t / V$ for urea using a single pool kinetic model [7]. We also measured systolic and diastolic blood pressure just before the start of HD.

Immunoglobulin (Ig), transthyretin, transferrin, retinolbinding protein, free fatty acid, ceruloplasmin, $\beta_{2^{-}}$ microglubulin, and intact parathyroid measurement were entrusted to Bio-Medical Laboratories, Inc. (Tokyo, Japan). Total, free, and acylcarnitine were also measured by enzyme cycling methods. Serum interleukin-6 (IL-6) was determined with a Quantikine ELISA kit (R\&D Systems, Inc., Minneapolis, MN, USA).

Natural killer (NK) cell activity was measured using a standard ${ }^{51} \mathrm{Cr}$ release assay against $\mathrm{K} 562$ (a highly undifferentiated and granulocytic myelogenous leukemia cell line from blast crisis) as reference target cells with 6-h incubation. NK activity was expressed as the $\mathrm{E}$ (effector cell)/T (target cell) ratio (reference ranges; $\mathrm{E}: \mathrm{T}$ ratio $=20: 1: \quad 17.1-48.7 \%$ and $\mathrm{E}: \mathrm{T}$ ratio $=10: 1$ : 8.9-29.5\%). Cluster of differentiation (CD) 4/CD8 was implemented by flow cytometry with the use of FACSCalibur $^{\mathrm{mm}}$ (BD Biosciences, San Jose, CA, USA) and KX-21 (Sysmex, Kobe, Japan). Serum soluble interleukin-2 receptor (IL-2R) was also measured using enzyme-linked immunoassay kits (reference, 122$496 \mathrm{U} / \mathrm{mL})$.

The serum selenium, zinc, and copper levels were measured by atomic absorption spectrophotometry (reference ranges; selenium, 107-171 $\mu \mathrm{g} / \mathrm{dL}$; zinc, 59$135 \mu \mathrm{g} / \mathrm{dL}$; and copper, $66-130 \mu \mathrm{g} / \mathrm{dL}$ ).

\section{Nutritional assessment}

Ideal body weight (BW) was defined as that calculated from the patients' heights using a body mass index (BMI) of $22.0 \mathrm{~kg} / \mathrm{m}^{2}$. BMI was calculated as dry weight in kilograms divided by the square of the height in meters. We calculated Onodera's prognostic nutrition index (PNI) using serum albumin, total lymphocytes (TLC), and dry BW as follows: PNI $=[10 \times$ albumin $(\mathrm{g} / \mathrm{dL})]+[0.005 \times \mathrm{TLC}][8]$. We also determined geriatric nutritional risk index (GNRI) as follows: GNRI $=[14.89 \times$ albumin $(\mathrm{g} / \mathrm{dL})]+[41.7 \times$ dry/ideal BW]. When DW was greater than the ideal weight, GNRI was calculated as a DW/ideal BW ratio identical to 1.0 [9]. 
We determined normalized protein catabolic rate (nPCR) and percentile creatinine generation rate (\%CGR), which can estimate dietary protein intake and skeletal muscle mass, respectively $[7,10]$.

\section{Anthropometric parameters}

At the start and end of the study, we measured the midarm circumference (MAC) and triceps skinfold thickness (TSF) using skinfold calipers on the limb not used for vascular access after a HD session. We calculated the midarm muscle circumference (MAMC) using MAC and TSF as follows: $\mathrm{MAMC}=\mathrm{MAC}-(\mathrm{TSF} \times 3.14)$. All measurements were performed by the same trained researcher.

We also determined the thigh muscle area by computed tomography (CT; Aquilion ONE TSX-301A, Toshiba, Tokyo, Japan). Each patient was examined in the supine position with the thigh muscle relaxed. An axial CT image was obtained at the midpoint of a line extending from the superior border of the patella to the greater trochanter of the femora. The thickness of the slice was $10 \mathrm{~mm}$. The thigh muscle area and bone area in the thigh were determined using SCFM-001A software (Toshiba, Tokyo, Japan). We used the standardized thigh muscle area (TMA) divided by the thigh bone area (TBA) to avoid the influence of body size, a surrogate marker of thigh sarcopenia [11].

\section{Handgrip strength}

We measured handgrip strength on the upper part of the arm not used for vascular access just before a HD session using a Smedley handgrip dynamometer. Each patient made two maximum force attempts, with an interval of at least $1 \mathrm{~min}$ between attempts. The highest recording was taken as the handgrip strength reading.

\section{M-mode echocardiography}

M-mode echocardiography was conducted on a nondialysis day at study entry and at 6 months. All measurements were conducted by the same trained physician.

Left ventricular systolic function was assessed as ejection fraction (EF) and fractional shortening (FS). EF and FS were calculated as follows: EF $(\%)=($ left ventricular end-diastolic volume (LVEDV)-left ventricular end-systolic volume (LVESV)) / LVEDV $\times 100$ and FS $(\%)=($ left ventricular end-diastolic dimension (LVDd) - left ventricular end-systolic dimension (LVDs)) / LVDd $\times 100$.

Left ventricular mass (LVM) was calculated as follows: LVM $(\mathrm{g})=1.04 \times[(\mathrm{LVDd}+$ interventricular septum (IVS) + left ventricular posterior wall end-diastolic thickness $\left.(\mathrm{LVPW}))^{3}-\mathrm{LVDd}^{3}\right]-14$. LVM was adjusted as to the body surface area in square meters and expressed as the left ventricular mass index (LVMI).

\section{Chest X-ray}

The cardiothoracic ratio (CTR) was measured on a chest $\mathrm{X}$-ray just before HD therapy by a trained researcher.

\section{Statistical analysis}

For statistical analysis, JMP (Version 11.1.1, SAS Institute, Cary, NC, USA) was used. Descriptive results were expressed as the means \pm standard deviation (SD). Parametric analyses were performed using Student's $t$-test, and the Wilcoxon $t$ test was used for non-parametric analyses. A value of $p<0.05$ was considered statistically significant different.

\section{Results}

\section{Basal characteristics}

During the follow-up, since we had lost five patients due to death $(n=4)$ and acute infection $(n=1)$, we finally analyzed a total of 21 patients.

Table 1 presents the basal characteristics. The mean age was $73.5 \pm 11.6$ years old, with an average time on HD of $60 \pm 84$ months. The causes of end-stage kidney disease were as follows: diabetic nephropathy in nine, hypertensive nephrosclerosis in four, chronic glomerulonephritis in two, others in three, and unknown in three.

Table 1 Characteristics of the study population

\begin{tabular}{ll}
\hline No. & 21 \\
Duration of hemodialysis (months) & $60 \pm 84$ \\
Age (years) & $73.5 \pm 11.6$ \\
Gender (male/female) & $12 / 9$ \\
Dry weight (kg) & $48.0 \pm 12.5$ \\
Body height (cm) & $158.0 \pm 10.5$ \\
BMI (kg/m²) & $19.0 \pm 3.2$ \\
Comorbidity & \\
$\quad$ Cardiovascular disease (\%) & 23.8 \\
Cerebral vascular disease (\%) & 19.0 \\
HCV Ab-positivity (\%) & 19.0 \\
Laboratory parameters & \\
Blood urea nitrogen (mg/dL) & $47.5 \pm 15.5$ \\
Creatinine (mg/dL) & $6.9 \pm 2.8$ \\
$\beta_{2}-M G$ (mg/L) & $25.0 \pm 8.1$ \\
Intact PTH (pg/mL) & $90 \pm 88$ \\
\hline
\end{tabular}

Data, means \pm SD

$B M I$ body mass index, $H C V A b$ anti-hepatitis $C$ antibody, $\beta_{2}-M G \beta_{2}$-microglobulin, PTH parathyroid hormone, SD standard deviation 


\section{Carnitine levels}

L-carnitine supplementation had normalized the serum total, free, and acylcarnitine levels at 3 months. The total carnitine levels were increased from $31.1 \pm 10.0$ to $98.6 \pm 27.9$ (normal, 45.0-91.0) $(p<0.001)$, the free carnitine levels from $19.8 \pm 6.6$ to $63.3 \pm 14.3$ (normal, 36.0-76.0) $(p<0.001)$, and the acylcarnitine levels from $11.4 \pm 4.9$ to $35.3 \pm 15.9$ (normal, 6.0-23.0) $\mu \mathrm{mol} / \mathrm{L}$ $(p<0.001)$ at 6 months (Fig. 1). However, there was no difference in free to acylcarnitine ratio between before $(1.92 \pm 0.14)$ and after the treatment $(1.98 \pm 0.10)$.

The final dosage of L-carnitine was $191 \pm 114 \mathrm{mg} /$ day $(4.0 \pm 2.1 \mathrm{mg} / \mathrm{kg} \mathrm{DW} /$ day). No difference was found in L-carnitine dosage between HD patients with preserved residual kidney function $(3.8 \mathrm{mg} / \mathrm{kg} \mathrm{DW} /$ day, $n=7)$ and those without (4.5 $\mathrm{mg} / \mathrm{kg} \mathrm{DW} /$ day, $n=14)$.

\section{Nutritional parameters}

Despite the identical DW, significant increases were found in the serum transferrin $(p<0.01)$, retinol-blinding protein $(p<0.05)$, and triglyceride levels $(p<0.05)$ (Table 2$)$. In contrast, GNRI, PNI, nPCR, and \%CGR did not change during the follow-up.

\section{Anthropometric parameters}

TSF was significantly increased from $0.4 \pm 0.3$ to $0.6 \pm$ $0.3 \mathrm{~cm}(p<0.05)$, while MAC and MAMC were not. There was no difference in the TMA/TBA ratio or handgrip strength during the treatment (Table 2). L-carnitine did not change as to the TMA/TBA ratio in the males $(10.1 \pm 3.3$ vs. $9.7 \pm 3.3)$ or females $(8.0 \pm 2.2$ vs. $7.8 \pm 2.6)$. Handgrip strength was also identical between males ( $20 \pm 6$ vs. $21 \pm 6 \mathrm{~kg}$ ) and females $(9 \pm 6$ vs. $8 \pm 6 \mathrm{~kg})$.

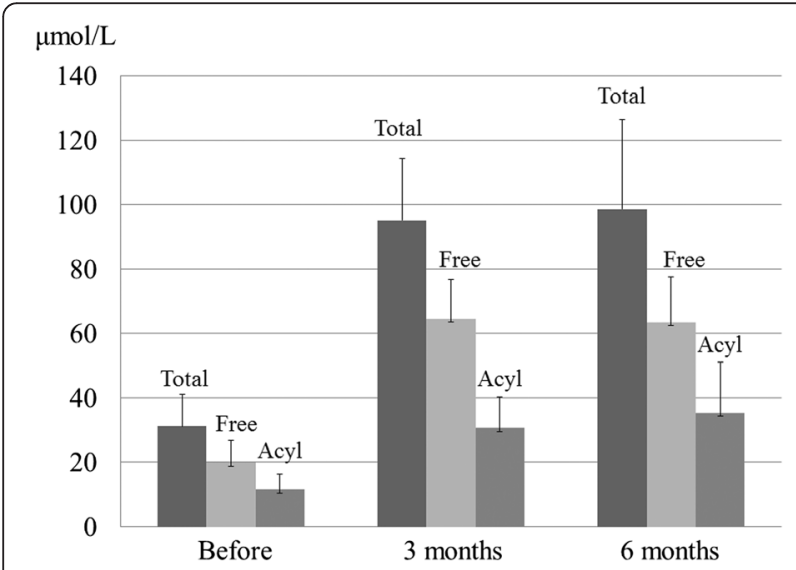

Fig. 1 Changes in serum total, free, and acylcarnitine levels following the 6-month L-carnitine supplementation. L-carnitine supplementation for 6 months normalized the total carnitine levels from $31.1 \pm 10.0$ to $98.6 \pm 27.9$ (normal, 45.0-91.0), the free carnitine levels from 19.8 \pm 6.6 to $63.3 \pm 14.3$ (normal 36.0-76.0), and the acylcarnitine levels from $11.4 \pm 4.9$ to $35.3 \pm 15.9$ (normal, 6.0-23.0) $\mu \mathrm{mol} / \mathrm{L}$
Table 2 Effects of L-carnitine supplementation on nutritional parameters

\begin{tabular}{|c|c|c|c|}
\hline Variables & Before & 3 months & 6 months \\
\hline \multicolumn{4}{|l|}{ Laboratory parameters } \\
\hline Blood urea nitrogen $(\mathrm{mg} / \mathrm{dL})$ & $47.5 \pm 15.5$ & $42.9 \pm 12.0$ & $45.4 \pm 12.7$ \\
\hline Creatinine (mg/dL) & $6.9 \pm 2.8$ & $6.7 \pm 2.2$ & $6.6 \pm 2.3$ \\
\hline Albumin (g/dL) & $3.2 \pm 0.3$ & $3.1 \pm 0.4$ & $3.2 \pm 0.4$ \\
\hline Transthyretin (mg/dL) & $22.4 \pm 5.9$ & $22.5 \pm 6.5$ & $24.7 \pm 9.7$ \\
\hline Transferrin (mg/dL) & $154.9 \pm 40.5$ & $175.5 \pm 42.6^{* *}$ & $174.9 \pm 47.8^{* *}$ \\
\hline Retinol-binding protein (mg/dL) & $8.9 \pm 2.5$ & $9.2 \pm 2.8$ & $10.0 \pm 3.4^{*}$ \\
\hline Total lymphocyte count $(/ \mu \mathrm{L})$ & $1190 \pm 440$ & $1250 \pm 610$ & $1150 \pm 430$ \\
\hline HDL cholesterol (mg/dL) & $41 \pm 13$ & $44 \pm 13$ & $43 \pm 14$ \\
\hline LDL cholesterol (mg/dL) & $73 \pm 21$ & $77 \pm 27$ & $81 \pm 29^{*}$ \\
\hline Triglyceride (mg/dL) & $91 \pm 56$ & $107 \pm 81$ & $103 \pm 58^{*}$ \\
\hline Free fatty acid (mEq/L) & $0.2 \pm 0.3$ & $0.2 \pm 0.2$ & $0.1 \pm 0.1$ \\
\hline Ceruloplasmin (mg/dL) & $22.5 \pm 4.9$ & $23.2 \pm 10.3$ & $22.6 \pm 4.7$ \\
\hline Hemoglobin (g/dL) & $10.0 \pm 1.2$ & $10.2 \pm 2.0$ & $10.2 \pm 1.7$ \\
\hline Ammonia $(\mu \mathrm{g} / \mathrm{dL})$ & $21 \pm 10$ & $32 \pm 10^{* *}$ & $36 \pm 13^{* *}$ \\
\hline \multicolumn{4}{|l|}{ Nutritional assessment index } \\
\hline GNRI & $83.9 \pm 7.9$ & $82.3 \pm 7.8$ & $82.7 \pm 8.8$ \\
\hline PNI & $38.2 \pm 3.7$ & $37.5 \pm 4.3$ & $37.3 \pm 4.8$ \\
\hline $\mathrm{nPCR}$ & $0.73 \pm 0.04$ & $0.66 \pm 0.03$ & $0.70 \pm 0.04$ \\
\hline$K t / V$ for urea & $1.3 \pm 0.1$ & $1.3 \pm 0.1$ & $1.4 \pm 0.1$ \\
\hline$\% C G R$ & $69.5 \pm 6.8$ & $65.7 \pm 5.5$ & $63.9 \pm 5.4$ \\
\hline \multicolumn{4}{|l|}{ Anthropometric parameters } \\
\hline Dry weight (kg) & $48.0 \pm 12.5$ & $47.8 \pm 12.1$ & $47.7 \pm 11.7$ \\
\hline BMI (kg/m2) & $19.0 \pm 3.2$ & $18.9 \pm 3.0$ & $18.8 \pm 2.9$ \\
\hline $\mathrm{TMA}^{\mathrm{T}} \mathrm{BA}$ ratio ${ }^{\mathrm{a}}$ & $9.1 \pm 3.0$ & ND & $8.8 \pm 3.1$ \\
\hline Handgrip strength $(\mathrm{kg})^{\mathrm{b}}$ & $16.0 \pm 8.1$ & ND & $16.1 \pm 8.6$ \\
\hline $\mathrm{MAC}(\mathrm{cm})$ & $21.8 \pm 3.1$ & ND & $23.1 \pm 3.8$ \\
\hline $\mathrm{TSF}(\mathrm{cm})$ & $0.4 \pm 0.3$ & ND & $0.6 \pm 0.3^{*}$ \\
\hline MAMC (cm) & $20.5 \pm 3.1$ & ND & $21.3 \pm 3.6$ \\
\hline
\end{tabular}

$B M I$ body mass index, GNRI geriatric nutritional risk index, $P N I$ prognostic nutrition index, $n P C R$ normalized protein catabolic rate, $K t / N$ for urea clearance of urea normalized to total body water using a single pool model, \%CGR creatinine generation rate, $H D L$ high-density lipoprotein, $L D L$ low-density lipoprotein, TMA thigh muscle area, TBA thigh bone area, MAC midarm circumference, TSF triceps skinfold thickness, MAMC midarm muscle circumference, $N D$ not done, $S D$ standard deviation

${ }^{*} p<0.05,{ }^{* *} p<0.01$ vs. before treatment. Data, means \pm SD

${ }^{a}$ Data were available for 20 out of 21 patients

${ }^{b}$ Data were available for 16 out of 21 patients

\section{Immunological and inflammatory markers}

A significant increase in NK cell activity was found at $\mathrm{E} / \mathrm{T}$ ratio of both $10: 1(10.2 \pm 8.8$ vs. $12.6 \pm 12.4 \%$; normal, 8.9-29.5 \%) $(p<0.02)$ and 20:1 (17.2 \pm 14.1 vs. $20.8 \pm 17.7 \%$; normal, $17.1-48.7 \%)(p<0.01)$. In contrast, the $\mathrm{CD} 4 / \mathrm{CD} 8$ ratio, serum CRP, and soluble interleukin-2 receptor (sIL-2R) did not change during the 6-month follow-up. The mean serum IL-6 level had rather increased from $5.2 \pm 2.5$ to $7.8 \pm 5.1$ at 
3 months $(p<0.05)$, and to $7.7 \pm 5.0 \mathrm{pg} / \mathrm{mL}$ at 6 months $(p=0.051)$ (Table 3$)$.

\section{Trace elements}

Serum selenium significantly decreased from $60.4 \pm 13.9$ to $52.4 \pm 12.2 \mu \mathrm{g} / \mathrm{L}$ during the follow-up $(p=0.01)$. The serum zinc and copper levels did not change (Table 3).

\section{Cardiac parameters}

L-carnitine increased as to FS from $42.2 \pm 11.4$ to $46.1 \pm$ $9.8 \%(p<0.01)$. There was no difference in the CTR, EF, and LVMI values between the two measurements. However, predialysis BNP had significantly decreased from $621.4 \pm 666.8$ to $412.0 \pm 426.0 \mathrm{pg} / \mathrm{mL}$ after the 6 -month supplementation $(p<0.02)$ (Table 4$)$.

\section{Discussion}

In this study, we orally administered L-carnitine to maintain the serum levels of free carnitine within normal range for 6 months by carefully monitoring and modifying the dosage during the first 3 months. As a result, we kept the free carnitine levels within normal range despite a relatively lower dose (3.8 to $4.5 \mathrm{mg} / \mathrm{kg}$ $\mathrm{BW} /$ day) compared to the recommended dosage (5 to $10 \mathrm{mg} / \mathrm{kg} \mathrm{BW/day).}$

We also showed that the regimen of L-carnitine supplementation had several beneficial effects on nutritional, immunological, and cardiac parameters, as follows.

\section{Effects on nutrition}

L-carnitine supplementation is reported to improve nutritional status in HD patients. Oral L-carnitine

Table 3 Effects of L-carnitine supplementation on immunological, inflammatory parameters, and trace elements

\begin{tabular}{llll}
\hline Variables & Before & 3 months & 6 months \\
\hline $\begin{array}{l}\text { Immunological and inflammatory } \\
\text { parameters }\end{array}$ & & & \\
NK cell activity; E/T ratio 10:1 (\%) & $10.2 \pm 8.8$ & $10.5 \pm 9.9$ & $12.6 \pm 12.4^{*}$ \\
$\quad$ E/T ratio 20:1 (\%) & $17.3 \pm 14.1$ & $17.4 \pm 15.3$ & $20.8 \pm 17.7^{* *}$ \\
CD4/CD8 ratio & $2.2 \pm 3.3$ & $2.0 \pm 2.2$ & $2.1 \pm 2.3$ \\
IgG (mg/dL) & $1460 \pm 410$ & $1430 \pm 350$ & $1490 \pm 400$ \\
IL-6 (pg/mL) & $5.2 \pm 2.5$ & $7.8 \pm 5.1^{*}$ & $7.7 \pm 5.0$ \\
slL-2R (U/mL) & $1311 \pm 1020$ & $1103 \pm 448$ & $1233 \pm 498$ \\
C-reactive protein (mg/dL) & $0.6 \pm 1.0$ & $0.6 \pm 0.9$ & $1.0 \pm 1.8$ \\
Trace elements & & & \\
Selenium $(\mu \mathrm{g} / \mathrm{L})$ & $60.4 \pm 13.9$ & $63.5 \pm 17.0$ & $52.4 \pm 12.2^{*}$ \\
Zinc $(\mu \mathrm{g} / \mathrm{dL})$ & $48.5 \pm 8.6$ & $52.3 \pm 10.1$ & $51.7 \pm 9.6$ \\
Copper $(\mu \mathrm{gg} / \mathrm{dL})$ & $94.0 \pm 19.1$ & $90.8 \pm 21.9$ & $91.4 \pm 23.0$
\end{tabular}

NK cell natural killer cell, $E / T$ ratio effector cells/target cells ratio, $C D$ cluster of differentiation, IgG immunoglobulin G, IL-6 interleukin-6, sIL-2R soluble interleukin-2 receptor, $S D$ standard deviation

${ }^{*} p<0.05,{ }^{* *} p<0.01$ vs. before treatment. Data, means \pm SD
Table 4 Effects of L-carnitine supplementation on cardiac parameters

\begin{tabular}{lll}
\hline Variables & Before & 6 months \\
\hline Systolic blood pressure (mmHg) & $156.6 \pm 3.4$ & $155.0 \pm 2.9$ \\
Diastolic blood pressure (mmHg) & $76.6 \pm 3.2$ & $73.4 \pm 2.9$ \\
Antihypertensive medication & & \\
$\quad$ Diuretics (\%) & 23.8 & 19.0 \\
a-blocker (\%) & 4.8 & 4.8 \\
B-blocker (\%) & 23.8 & 23.8 \\
Calcium antagonist (\%) & 42.9 & 42.9 \\
Angiotensin II type 1 receptor blocker (\%) & 47.6 & 52.4 \\
M-mode echocardiography & & \\
EF (\%) & $69.1 \pm 10.8$ & $69.8 \pm 10.5$ \\
FS (\%) & $42.2 \pm 11.4$ & $46.1 \pm 9.8^{* *}$ \\
LVDd (cm) & $4.5 \pm 0.9$ & $4.6 \pm 0.8$ \\
LVDs (cm) & $2.6 \pm 0.9$ & $2.5 \pm 0.8$ \\
IVS (mm) & $14 \pm 3$ & $15 \pm 3$ \\
LVPW (cm) & $1.4 \pm 0.2$ & $1.3 \pm 0.3$ \\
LVM (g) & $308.2 \pm 131.1$ & $303.5 \pm 104.4$ \\
LVMI (g/m ${ }^{2}$ ) & $217.8 \pm 100.2$ & $212.3 \pm 77.3$ \\
Chest X-ray & & \\
CTR (\%) & $52.8 \pm 5.3$ & $52.4 \pm 5.0$ \\
Laboratory data & & \\
BNP (pg/mL) & $621.4 \pm 666.8$ & $412.0 \pm 426.0^{*}$ \\
\hline
\end{tabular}

$E F$ ejection fraction, FS fractional shortening, LVDd left ventricular end-diastolic dimension, $L V D$ s left ventricular end-systolic dimension, IVS interventricular septal thickness, LVPW left ventricular posterior wall end-diastolic thickness, LVFS left ventricular fractional shortening, LVM left ventricular mass, LVMI left ventricular mass index, CTR cardiothoracic ratio, BNP: brain natriuretic peptide, $S D$ standard deviation

${ }^{*} p<0.05,{ }^{* *} p<0.01$ vs. before treatment. Data, means \pm SD

administration increased nPCR independently of dialysis dose [12]. L-carnitine also improved nutritional parameters such as serum transferrin and albumin in HD patients $[13,14]$. Intravenous administration of L-carnitine $(2 \mathrm{~g})$ at the end of a HD session also increases the morphological diameters of skeletal muscle fibers [15]. L-carnitine treatment prevented deterioration of the peak rate of oxygen consumption $\left(\mathrm{VO}_{2} \max \right)$ [16].

In this study, L-carnitine significantly increased serum retinol-binding protein and transferrin 6 months later. In addition, the treatment increased serum ammonia despite within the normal range, indicating a possibility that $\mathrm{L}$-carnitine may enhance ammonia production via urea cycle by increased food intake. However, nPCR, an indirect marker of dietary protein intake, remained lower during the study. L-carnitine also did not improve other nutritional parameters such as GNRI and PNI. There was no difference in muscle mass area, handgrip power, and \%CGR. These findings convincingly suggest that oral L-carnitine treatment for 6 months to maintain 
serum-free carnitine within normal range did not alleviate poor nutritional status.

In contrast, TSF was significantly increased after the treatment. However, since TMA/TBA ratio, a marker of thigh skeletal mass area, was rather decreased from $9.1 \pm 3.0$ to $8.8 \pm 3.1$ despite no gain of body weight, it might be explained by the changes in regional body composition due to progressive sarcopenia at the upper arm.

\section{Effects on immune response}

NK cells activity plays an important role in the defense mechanism against infections and tumors. In HD patients, the activity of NK cells is either lowered or unchanged [17]. A higher CD4/CD8 ratio, a marker of Ig production by $\mathrm{B}$ cells, is also associated with a better serological response to hepatitis $B$ vaccination [18].

$\mathrm{L}$-carnitine can restore the age-related changes in neutrophil function such as chemotactic and phagocytic activity in vitro [19]. L-carnitine treatment also prevented agent-induced experimental colitis by abrogation of both innate and adaptive immune responses in mice [20]. In addition, L-carnitine can reduce the apoptotic levels of $\mathrm{CD} 4^{+}$and $\mathrm{CD} 8^{+}$cells [21].

In the present study, L-carnitine supplementation significantly increased NK cell activity at $\mathrm{E} / \mathrm{T}$ ratios of 10:1 and 20:1, but it first became evident at 6 months. So, at least more than 3 months will be needed to restore NK cell activity following L-carnitine therapy. Selenium deficiency is potentially associated with cellular immunity in HD patients [17]. However, serum selenium was rather decreased from $60.4 \pm 13.9$ to $52.4 \pm 12.2 \mu \mathrm{g} / \mathrm{L}$ after the supplementation, suggesting no association of selenium deficiency with restored NK cell activity.

\section{Effects on cardiac parameters}

L-carnitine prevents the development of ventricular fibrosis and heart failure with preserved EF in hypertensive heart disease [22]. L-carnitine also blocks dietary vitamin B deficiency-induced left ventricular dysfunction and attenuates the diet-caused increase in serum BNP [23]. In patients with chronic heart failure, the plasma carnitine levels are correlated with \%FS, EF, and LVMI [24]. A meta-analysis also revealed that L-carnitine is associated with a $27 \%$ reduction in all-cause mortality and a $40 \%$ reduction in angina symptoms in patients experiencing acute myocardial infarction [25].

It has been reported that oral L-carnitine treatment significantly improved left ventricular function [26, 27], while it reduced LVMI [28]. In this study, we confirmed that L-carnitine supplementation caused a significant increase in \%FS concomitantly with a reduction of BNP. In contrast, L-carnitine did not change LVMI. The reason for this discrepancy remains unknown, but it may be partly due to the shorter period of supplementation than in the previous study (12 months) [28].

\section{Effects on inflammation}

A link between inflammation and carnitine deficiency has been well suggested in HD patients. However, the results of the recent two meta-analysis studies involving randomized controlled trials did not coincide; one study [29] showed that L-carnitine significantly decreased serum CRP, whereas the other disclosed no effect [30].

In this study, oral L-carnitine did not change the serum CRP level, while it rather increased the serum IL-6 level after 6 months. Because it is reported that oral administration of $1000 \mathrm{mg} / \mathrm{kg} \mathrm{BW}$ of L-carnitine decreased serum CRP and IL-6 [31, 32], a higher dose may be required to alleviate the uremia-related inflammatory response.

\section{Study limitations}

There are several limitations to this study. Firstly, this study was not carried out in a randomized controlled manner, and the number of patients was clearly small. So, future studies involving more samples are needed to confirm the association of L-carnitine treatment and clinical parameters. Secondly, we simply compared a lot of clinical markers before and after L-carnitine treatment. So, it remains unknown whether or not these immunological and echocardiographic alterations may lead to beneficial effects on clinical outcomes. Thirdly, since we administered L-carnitine orally at a relatively low dose, its effect may be limited compared to intravenous administration. Fourthly, we did not measure the appendicular skeletal mass index using bioelectrical impedance (BIA) or dual-energy X-ray absorptiometry, so we could not precisely confirm the presence of sarcopenia. Finally, muscle atrophy progresses over time, so it will be necessary to evaluate the effect of L-carnitine in the long term.

\section{Conclusions}

We showed that L-carnitine supplementation had several effects on clinical parameters. L-carnitine increased NK cell activity following the 6-month treatment. There was a significant increase in \%FS with a decrease in BNP. The findings suggested that L-carnitine can improve immunological and LV-related systolic functional parameters. In contrast, L-carnitine did not ameliorate sarcopenic markers and did not reduce the inflammatory response. So, future well-designed RCT is obviously needed to confirm the multidirectional actions of L-carnitine supplementation in patients on regular HD. 


\section{Abbreviations}

\%CGR: creatinine generation rate; BIA: bioelectrical impedance; BNP: brain natriuretic peptide; BW: body weight; $C D$ : cluster of differentiation; CKD: chronic kidney disease; CRP: C-reactive protein; CT: computed tomography; CTR: cardiothoracic ratio; DW: dry weight; E/T ratio: effector cells/target cells ratio; EF: ejection fraction; FS: fractional shortening; GNRI: geriatric nutritional risk index; HD: hemodialysis; HDL: high-density lipoprotein; Ig: immunoglobulin; IL-6: interleukin-6; IVS: interventricular septal thickness; LDL: low-density lipoprotein; LVDd: left ventricular end-diastolic dimension; LVDs: left ventricular end-systolic dimension; LVEDV: left ventricular end-diastolic volume; LVESV: left ventricular end-systolic volume; LVM: left ventricular mass; LVMI: left ventricular mass index; MAC: midarm circumference; MAMC: midarm muscle circumference; NK: natural killer; nPCR: normalized protein catabolic rate; PEW: protein-energy wasting; PNI: prognostic nutrition index; RRFC: rate of reabsorption of free carnitine; SIL-2R: soluble interleukin-2 receptor; TBA: thigh bone area; TLC: total lymphocyte count; TMA: thigh muscle area; TSF: triceps skinfold thickness.

\section{Competing interests}

None of the authors have any conflict of interest to disclose.

\section{Authors' contributions}

HS, conception and design, data collection, data analysis and interpretation, and manuscript writing; AK, conception and design, data analysis and interpretation, and final approval of the manuscript; $\mathrm{HO}$, conception and design, support of preparation, and drafting of the manuscript; RS and $\mathrm{HO}$, general management and critical reading and discussion of the manuscript. All authors discussed the results and commented on the manuscript. All authors read and approve the final manuscript.

\section{Authors' information}

HS is a graduate student at the Department of Gastroenterological and Transplant Surgery, Applied Life Sciences, Institute of Biomedical and Health Sciences, Hiroshima University. AK is a professor at Blood Purification Unit, Hamamatsu University Hospital. RS is the Director of National Hospital Organization Yanai Medical Center. $\mathrm{HO}$ is the Chief Medical Director at the Department of Pediatrics and Director of the Research Department in National Hospital Organization Yanai Medical Center. $\mathrm{HO}$ is a professor at the Department of Gastroenterological and Transplant Surgery, Applied Life Sciences, Institute of Biomedical and Health Sciences, Hiroshima University.

\section{Acknowledgements}

We greatly thank $\mathrm{H}$. Takesue for performing the echocardiography, C. Takeuch for the anthropometric measurements, and K. Uehara for the thigh CT measurements.

\section{Author details}

'Department of Gastroenterological and Transplant Surgery, Applied Life Sciences, Institute of Biomedical and Health Sciences, Hiroshima University, 1-2-3 Kasumi, Minami-ku, Hiroshima 734-8551, Japan. ${ }^{2}$ Blood Purification Unit, Hamamatsu University Hospital, 1-20-1 Handayama, Higashi-ku, Hamamatsu, Shizuoka 431-3192, Japan. ${ }^{3}$ Department of Surgery, National Hospital Organization Yanai Medical Center, 95 Ihonosho, Yanai, Yamaguchi 742-1352, Japan. ${ }^{4}$ Department of Pediatrics, National Hospital Organization Yanai Medical Center, 95 Ihonosho, Yanai, Yamaguchi 742-1352, Japan.

\section{Received: 3 July 2015 Accepted: 8 September 2015}

\section{Published online: 24 November 2015}

\section{References}

1. Carrero JJ, Stenvinkel P, Cuppari L, Ikizler TA, Kalantar-Zadeh K, Kaysen G, et al. Etiology of the protein-energy wasting syndrome in chronic kidney disease: a consensus statement from the International Society of Renal Nutrition and Metabolism (ISRNM). J Ren Nutr. 2013:23:77-90.

2. Ozaki K, Sano T, Tsuji N, Matsuura T, Narama I. Carnitine is necessary to maintain the phenotype and function of brown adipose tissue. Lab Invest. 2011;91:704-10.

3. Minkler PE, Brass EP, Hiatt WR, Ingalls ST, Hoppel CL. Quantification of carnitine, acetylcarnitine, and total carnitine in tissues by high-performance liquid chromatography: the effect of exercise on carnitine homeostasis in man. Anal Biochem. 1995;231:315-22.
4. Evans AM, Faull RJ, Nation RL, Prasad S, Elias T, Reuter SE, et al. Impact of hemodialysis on endogenous plasma and muscle carnitine levels in patients with end-stage renal disease. Kidney Int. 2004;66:1527-34.

5. Debska-Slizień A, Kawecka A, Wojnarowski K, Zadrony D, Kunicka D, Krol E, et al. Carnitine content in different muscles of patients receiving maintenance hemodialysis. J Ren Nutr. 2007;17:275-81.

6. Koeth RA, Wang Z, Levison BS, Buffa JA, Org E, Sheehy BT, et al. Intestinal microbiota metabolism of $\mathrm{L}$-carnitine, a nutrient in red meat, promotes atherosclerosis. Nat Med. 2013;19:576-85.

7. Shinzato T, Nakai S, Fujita Y, Takai I, Morita H, Nakane K, et al. Determination of $\mathrm{Kt} / \mathrm{V}$ and protein catabolic rate using pre- and postdialysis blood urea nitrogen concentrations. Nephron. 1994;67:280-90.

8. Onodera T, Goseki N, Kosaki G. Prognostic nutritional index in gastrointestinal surgery of malnourished cancer patients. Nihon Geka Gakkai Zasshi. 1984;85:1001-5 [Article in Japanese].

9. Yamada K, Furuya R, Takita T, Maruyama Y, Yamaguchi Y, Ohkawa S, et al. Simplified nutritional screening tools for patients on maintenance hemodialysis. Am J Clin Nutr. 2008;87:106-13.

10. Shinzato T, Nakai S, Miwa M, Iwayama N, Takai I, Matsumoto Y, et al. New method to calculate creatinine generation rate using pre- and postdialysis creatinine concentrations. Artif Organs. 1997:21:864-72.

11. Kato A, Ishida J, Endo Y, Takita T, Furuhashi M, Maruyama Y, et al. Association of abdominal visceral adiposity and thigh sarcopenia with changes of arteriosclerosis in hemodialysis patients. Nephrol Dial Transplant. 2011;26:1967-076.

12. Trovato GM, lannetti E, Murgo AM, Carpinteri G, Catalano D. Body composition and long-term levo-carnitine supplementation. Clin Ther. 1998;149:209-14.

13. Savica V, Santoro D, Mazzaglia G, Ciolino F, Monardo P, Calvani M, et al. $\mathrm{L}$-carnitine infusions may suppress serum C-reactive protein and improve nutritional status in maintenance hemodialysis patients. J Ren Nutr. 2005:15:225-30

14. Duranay M, Akay H, Yilmaz FM, Senes M, Tekeli N, Yucel D. Effects of $\mathrm{L}$-carnitine infusions on inflammatory and nutritional markers in haemodialysis patients. Nephrol Dial Transplant. 2006;21:3211-4.

15. Giovenali P, Fenocchio D, Montanari G, Cancellotti C, D'lddio S, Buoncristiani $U$, et al. Selective trophic effect of L-carnitine in type I and Ila skeletal muscle fibers. Kidney Int. 1994;46:1616-9.

16. Brass EP, Adler S, Sietsema KE, Hiatt WR, Orlando AM, Amato A, et al. Intravenous L-carnitine increases plasma carnitine, reduces fatigue, and may preserve exercise capacity in hemodialysis patients. Am J Kidney Dis. 2001;27:1018-28.

17. Tanaka A, Kato A, Suzuki Y, Suzuki M, Ohmori $H$, Sumimoto $R$, et al. Association of increased indoleamine 2,3-dioxygenase with impaired natural killer cell activity in hemodialysis patients. Ther Apher Dial. 2014;18:19-23.

18. Sari F, Taskapan H. Good response to HBsAg vaccine in dialysis patients is associated with high $\mathrm{CD}^{+} / \mathrm{CD}^{+}$ratio. Int Urol Nephrol. 2012;44:1501-6

19. Izgut-Uysal VN, Agac A, Karadogan I, Derin N. Effects of L-carnitine on neutrophil functions in aged rats. Mech Ageing Dev. 2003;124:341-7.

20. Fortin G, Yurchenko K, Collette C, Rubio M, Villani AC, Bitton A, et al. L-carnitine, a diet component and organic cation transporter OCTN ligand, displays immunosuppressive properties and abrogates intestinal inflammation. Clin Exp Immunol. 2009;156:161-71.

21. Athanassakis I, Mouratidou M, Sakka P, Evangeliou A, Spilioti M, Vassiliadis S $L$-carnitine modifies the humoral immune response in mice after in vitro or in vivo treatment. Int Immunopharmacol. 2001;1:1813-22.

22. Omori Y, Ohtani T, Sakata Y, Mano T, Takeda Y, Tamaki S, et al. L-carnitine prevents the development of ventricular fibrosis and heart failure with preserved ejection fraction in hypertensive heart disease. J Hypertens. 2012;30:1834-44.

23. Strilakou AA, Lazaris AC, Perelas Al, Mourouzis IS, Douzis I, Karkalousos PL, et al. Heart dysfunction induced by choline-deficiency in adult rats: the protective role of L-carnitine. Eur J Pharmacol. 2013;709:20-7.

24. El-Aroussy W, Rizk A, Mayhoub G, Aleem SA, El-Tobgy S, Mokhtar MS. Plasma carnitine levels as a marker of impaired left ventricular functions. Mol Cell Biochem. 2000;213:37-41.

25. DiNicolantonio JJ, Lavie CJ, Fares H, Menezes AR, O'Keefe JH. L-carnitine in the secondary prevention of cardiovascular disease: systematic review and meta-analysis. Mayo Clin Proc. 2013;88:544-51. 
26. Matsumoto $Y$, Sato $M$, Ohashi $H$, Araki $H$, Tadokoro $M$, Osumi $Y$, et al. Effects of L-carnitine supplementation on cardiac morbidity in hemodialyzed patients. Am J Nephrol. 2000;20:201-7.

27. Kudoh Y, Aoyama S, Torii T, Chen Q, Nagahara D, Sakata H, et al. Hemodynamic stabilizing effects of L-carnitine in chronic hemodialysis patients. Cardiorenal Med. 2013;3:200-7.

28. Sakurabayashi T, Miyazaki S, Yuasa Y, Sakai S, Suzuki M, Takahashi S, et al. L-carnitine supplementation decreases the left ventricular mass in patients undergoing hemodialysis. Circ J. 2008;72:926-31.

29. Chen Y, Abbate M, Tang L, Cai G, Gong Z, Wei R, et al. L-carnitine supplementation for adults with end-stage kidney disease requiring maintenance hemodialysis: a systematic review and meta-analysis. Am J Clin Nutr. 2014;99:408-22.

30. Yang SK, Xiao L, Song PA, Xu X, Liu FY, Sun L. Effect of L-carnitine therapy on patients in maintenance hemodialysis: a systematic review and metaanalysis. J Nephrol. 2014;27:317-29.

31. Shakeri $A$, Tabibi $H$, Hadayati $M$. Effects of $L$-carnitine supplement on serum inflammatory cytokines, C-reactive protein, lipoprotein (a), and oxidative stress in hemodialysis patients with Lp (a) hyperlipoproteinemia. Hemodial Int. 2010;14:498-504.

32. Tabibi H, Hakeshzadeh F, Hedayati M, Malakoutian T. Effects of I-carnitine supplement on serum amyloid $\mathrm{A}$ and vascular inflammation markers in hemodialysis patients: a randomized controlled trial. J Ren Nutr. 2011;21:485-91.

\section{Submit your next manuscript to BioMed Central and take full advantage of:}

- Convenient online submission

- Thorough peer review

- No space constraints or color figure charges

- Immediate publication on acceptance

- Inclusion in PubMed, CAS, Scopus and Google Scholar

- Research which is freely available for redistribution 